It must be remembered that whaling in itself was not a seasonal trade, but that the whalers made voyages lasting from two to four years, catching whales wherever they could; so that the seasonal distribution of the catches of sperm whales is the more significant. The author promises to publish further plottings of suerm whale records and of records of five other species of whales from logs still unexamined, and the results of his investigations will be looked for with rnuch interest.

Records of present-day whaling are giving rise to serious conjecture with regard to the preservation of the number of whales. The number killed during the season 1929-30, according to the Norwegian Whaling Gazette, reached the record of 38,563 individuals. Of these, 19,080 were blue whales, 14,350 finners, 1923 humpback, 922 sei, 1352 sperm, and 936 other species. Of the total number, by far the greatest proportion was taken in antarctie waters, 30,654 ; Japanese waters followed with 1714 , and the remainder were captured in tropical and northern seas. The whaler Lansing itsel had a catch of 300 whales; shore stations in Alaska and British Columbia had 675. The slaughter of whales has become a much intensified process in recent years: the Norwegian antarctic whaler Sir James Clark Ross had seven steam whale-killing boats, a crew of 245 men, and had taken during the season 1445 whales, yielding 55,000 barrels of oil, which were sold to a soap-making firm at an estimated value of one and a half million dollars.

The total world-yield of whale-oil for the season exceeded $3,427,000$ barrels, so that, through overproduction, much oil had to be stored, and as a consequence there is a slacking off in whaling during the present season. It is a relief to know that the whales will suffer less during a season, but even a years' total respite would help little towards the preservation of slow-breeding creatures like whales, in face of the capacity for slaughter of the new whaling craft.

\title{
Chinese Materia Medica
}

T $\mathrm{N}$ an article in NATURE of June 7, 1930, a description was given of the progress that is being made in the elucidation of the botanical origin of Chinese vegetable drugs, and it was pointed out that what might at first sight appear to be a peculiarly abstruse investigation, in which medical historians and anthropologists alone could be concerned, has resulted in a revival of interest in Ephedra and the use of its principal alkaloid, ephedrine, in the treatment of asthma.

Prof. Bernard E. Read, to whose labours this practical outcome was mainly due, is continuing these studies, and has published in recent issues of the Peking Natural History Bulletin a series of papers on Chinese drugs of animal origin, which have now been issued as a reprint. In preparing these papers, the author has had at his disposal specimens and notes of work done on Chinese materia medica at the Severance Union Medical College, Seoul, and the results of an attempt made by Miss Blanche Wu of the Department of Biology, Yenching University, to arrange the whole fauna used in Chinese medicine according to a modern scientific classification. There is, however, so much unidentified material that such a classification is still impossible.
The subject-matter is arranged in five sections: Domestic Animals; Wild Animals ; Rodents; Monkeys and Supernatural Beings; and Man as a Medicine. In each of these sections the particular animals furnishing the drugs are dealt with, and much time and trouble has clearly been expended in relating the Chinese symbols and names to their precise English equivalents. The Chinese doctor was, and probably still is, quite catholic in his taste for drugs, and the article on the pig is reminiscent of the Chicago pork factory, where everything was used but the squeak. This catholicity is not confined to the parts of an animal used, but applies equally to the species regarded as coming within the scope of practical medicine, for man himself figures prominently as a source of drugs. In this respect Chinese medicine is no worse, as Prof. Read points out, than European medicine was in the sixteenth century, and, as he pleasantly puts it, the feverish activity with which every type of animal tissue is being examined for hormones, vitamins, and other specific agents for the treatment of disease "compels an open mind that one may reach beyond the unæsthetic setting of the subject to things worth while."

\section{Forms of Communal and Industrial Waste}

1 PAPER read by J. L. Hodgson before the Royal A Society of Arts on Jan. 20, diseussing "Some Aspects of the Problem of Industrial and Communal Waste ", included a number of highly controversial questions, but dealt with many matters which are the subject of much anxious thought to-day and, above all, merit the attention of scientific workers. The contrast between the immense potential productivity of the world, which is largely the result of the application of scientific method and discoveries, and the immense amount of poverty and unemployment which exists side by side with such productive powers, is essentially a challenge to scientific workers whose labours have been a vital factor in increasing the productive capacity of the world. Among other causes of the present position indicated by $\mathrm{Mr}$. Hodgson are not only the numerous forms of industrial waste, but also those forms of communal waste such as armaments, tariffs, unemployment, inadequate housing, sanitary, medical, and educational facilities, restrictions on transport, and, sometimes, forms of rationalisation which tend to reduce the wealth and services available within a community.
These forms of communal waste are the outcome partly of ignorance and partly of vested interests, and they only persist through the absence of impartial scientific inquiry and analysis on a scale competent and authoritative enough to compel rational action.

Among the factors responsible for the present situation, the concentration of credit power in the hands of socially irresponsible people is regarded as fundamental, and in its reaction on industry has encouraged continued increase of technical efficiency, the reduction of wages and staff, replacement of skilled by unskilled labour, mass-unemployment, the formation of mergers or trusts, the growth of tariffs, leading ultimately to restricted output and sabotage of excess products.

Mr. Hodgson, pointing out the absurdity of production which leads only to waste, suggested that strenuous efficiencies are surplus, and that if communal wastes are eliminated and routine work efficiently organised and shared by all, a comparatively small amount of routine will be required of each individual worker. Our aim should be to organise the produc. tion of the goods necessary for the maintenance and 
development of the community, or their purchase from outside in exchange for commodities produced at home, by the minimum expenditure of effort. In place of the existing credit system, the creation by the Treasury of notes to the value of goods and services available is suggested. These notes would be issued to individuals as wages or endowment, according to age, grade, or services rendered. No one would receive notes which are insufficient in value for the maintenance of a normal, ample life, and while suitable compulsion would be provided regarding a necessary two months' maintenance work, it would be unnecessary to fix an upper limit of remuneration since additional notes would be issued only for actual services and could not be loaned at interest. Under this system no taxation would be required, as the notes necessary to cover all national services would be withheld from distribution. Endowed Jeisure would be a prominent feature, and the system would definitely lead towards regional specialisation, the exchange between which would be by means of goods.

\section{Chromosome Studies and Plant Breeding}

THE breeding of plants with the object of obtaining new and improved varieties is at best a slow and laborious process, with chances of success by no means assured. Any means of prediction of the probable results of a cross would be of immense value, and Dr. Darlington shows in a series of eight papers 1 how far this object may be attained by a previous knowledge of the cytology of the forms to be crossed.

The author passes to the practical view of the question with the minimum of technical detail, and shows how very closely the behaviour of plants in breeding can be correlated with their visible chromosome behaviour. He gives us the picture of a fertile germ cell as carrying a set of chromosomes, which must represent a complete and balanced set of characters, for in exceptional cases such germ cells are able to develop into a new plant without fertilisation. Normally two sets of chromosomes come together at fertilisation and remain associated throughout vegetative growth until germ cells are formed again. In this latter process, an exact pairing of like chromosomes, which afterwards separate, one of each pair passing to each daughter nucleus, is usually associated with the production of fertile germ cells. Irregularity in this pairing frequently results in the production of unbalanced sets of characters in the germ cells, with loss or great reduction in fertility. This is a fundamental point in cross breeding, where the value of the hybrid depends on seed fertility, as in the case of cereals, cherries, and plums.

On the other hand, crosses between plants with different chromosome numbers, which result in sterile hybrids, may have advantages when the plant is required for ornamental purposes and can be propagated vegetatively.

Another interesting fact which has emerged from comparatively recent cytological work is that related species of plants often have either the same chromosome number or some multiple of a basic number: that is, they are naturally occurring 'polyploids'. Work on plants in cultivation and under cytological observation has brought forward facts which are most suggestive as to a possible way in which species may have been derived from one another. This is illustrated by the cross between Primula floribunda and $P$. verticillata, which results in a sterile hybrid. Occasional fertile seeds are, however, produced, and they give rise to plants with hybrid characters, but differing in being fertile and breeding true. Such seedlings-known as $P$. Kewensis-are found to contain twice the anticipated number of chromosomes, and as each parental set has been doubled in such plants, exact pairing is again possible with the passage of two complete balanced sets to each daughter nucleus. The relative numbers of chromosomes in naturally occurring species suggests that hybridisation followed by restoration of fertility by polyploidy is one possible method of their origin.

These and many other problems are dealt with fully in these papers. Although, as Dr. Darlington points out, the knowledge gained by a preliminary chromosome investigation cannot control the results obtained by a cross, it may be of great value in directing the activities of the plant breeder into lines which have some hope of success.

${ }^{1}$ Gard. Chron., vol. 90, Nos. 2332-2347; 1931.

\section{University and Educational Intelligence}

CAMbridge.-An appointment to a University lectureship in mathematics will be made in the Easter term, to take effect from Oct. 1. The initial basic stipend is $£ 200$ a year ; but an additional allowance of $£ 150$ a year may be granted to a lecturer who is not a fellow of a College, and also a number of years' seniority carrying with it an increased basic stipend. Candidates are requested to send their names, with any evidence of qualifications which they may desire to submit, to Mr. W. J. Harrison, Secretary of the Faculty Board of Mathematics, Clare College, Cambridge, on or before April 30.

The examiners consider that the following submitted essays of distinction for the Smith's prizes and Rayleigh prizes: D. W. Babbage (Magdalene College), "Cremona Transformations"; J. Bronowski (Jesus College), "On a Representation of Primals"; J. Cossar (Magdalene College), " On Fourier Integrals "; V. V. Narliker (Non-Collegiate), "Cosmogony and Astronomical Dynamics"; H. M. Taylor (Clare College), "The Anomalous Scattering of X-Rays". The Smith's prizes are awarded to D. W. Babbage and H. M. Taylor, and Rayleigh prizes to J. Cossar and V. V. Narliker.

Dr. J. A. Venn, Gilbey lecturer in agriculture in the University, has been elected president of Queens' College.

London.-The degree of D.Sc. in chemistry has been conferred on Frank Bell (Battersea Polytechnic) for a thesis entitled "Polarisation and Chemical Reactivity in Aromatic Substances" (J. Chem. Soc., 1928-30)

Applications are invited for the Henry George Plimmer fellowship in pathology of the Imperial College of Science and Technology, for research in morbid anatomy, histological anatomy, chemical pathology, protozoology, bacteriology, or allied subjects in either zoology, medicine, or botany. Applications must be made by letter to the Rector, Imperial College of Science and Technology, Prince Consort Road, S.W.7, by at latest June 11 .

AN election of Beit junior memorial fellows for medical research will take place in July next and applications for them are invited. The annual value of each fellowship is $£ 400$ and the tenure usually three years. Forms of application and full information may be obtained by letter addressed to Prof. T. R. Elliott, Honorary Secretary, Beit Memorial Fellowships for Medical Research, University College Hospital Medical School, University Street, W.C.1. Completed forms of application should be returned by May 18 .

No. 3255, VoL. 129] 